\title{
THE LEGEND OF "GUNUNG WURUNG" AS LOCAL WISDOM FOR TEACHING MATERIALS AND CHARACTER EDUCATION IN ELEMENTARY SCHOOL
}

\author{
Ngatman, Siti Fatimah \\ Universitas Sebelas Maret \\ ngatman@fkip.uns.id
}

\begin{tabular}{l} 
Article History \\
\hline accepted 30/09/2018 \\
approved 12/10/2018 \\
published 30/10/2018
\end{tabular}

\section{Keywords}

Legend of Gunung

Wurung, local wisdom, character education

\begin{abstract}
Natural phenomena formed on earth such as the formation of mountains can be used as a means for humans to always think and increase curiosity. In the world of education, natural phenomena can be used as a medium for learning. This study aims to analyze and study the legend of Gunung Wurung as a teaching material based on local wisdom and strengthening the character education in elementary school. The legend of Gunung Wurung is one of the folklore located Karangsambung area, Kebumen, Central Java. This research is a descriptive research. The research data was obtained from the results of observations and interviews with residents around the Karangsambung area and the results of the teacher perception questionnaire SDN 02 Kuwayuhan. Data analysis techniques used a qualitative descriptive approach. The results of the analysis show that: 1) The legend of Gunung Wurung turned out to be less well known to residents around the Karangsambung area; 2) The legend of Gunung Wurung can be used as an alternative material in thematic learning in elementary schools based on local wisdom; 2) Character education values in the legend of Gunung Wurung include religious character, respect and obedience, cooperation, hard work, social care, patience, and commitment.
\end{abstract}




\section{PENDAHULUAN}

Berdasarkan peraturan pemerintah Nomor 19 tahun 2005 tentang Standar Nasional Pendididikan pada pasal 17 (1) dijelaskan bahwa kurikulum tingkat satuan pendidikan SD/MI/SDLB, SMP/MTs/SMPLB, SMA/MA/SMALB, SMK/MAK, atau bentuk lain yang sederajat dikembangkan sesuai dengan satuan pendidikan, potensi daerah/karakteristik daerah, sosial budaya masyarakat setempat, dan peserta didik. Peraturan tersebut memberikan kesempatan yang lebih besar kepada satuan pendidikan untuk mengembangkan kurikulum yang disesuaikan dengan potensi dan budaya yang ada pada daerah masing-masing.Oktarina \& Ribuwati (2018) memaparkan bahwa pendidikan kearifan lokal merupakan sesuatu yang memiliki nilai sosial, artinya kearifan lokal yang terdapat dalam sebuah pendidikan memiliki nilai berupa nilai-nilai budaya daerah tersebut.Melalui pendidikan berbasis kearifan lokal, berbagai potensi yang dimiliki oleh suatu daerah dapat berkembang serta anak-anak pada suatu daerah dapat mengenal budaya serta nilai-nilai daerahnya sendiri.Dijelaskan pula bahwa kearifan lokal sangat identik dalam sebuah karya sastra yang menceritakan bahasa, status sosial atau panggilan seseorang.

Sastra merupakan wujud gagasan kreatif seseorang melalui pandangan terhadap lingkungan sosial yang berada di sekelilingnya dengan menggunakan bahasa yang indah. Sastra hadir sebagai hasil perenungan pengarang terhadap fenomena yang ada (Gusnetti, Syofiani, \& Isnanda: 2015). Berbagai ungkapan yang dapat ditemukan dalam suatu sastra dan bahasa dapat menjadi jembatan penghubung antara nilai sosial dan budaya dalam masyarakat.Keberadaan budaya daerah dan adat istiadat yang melahirkan pola kehidupan, tradisi dan bahasa daerah di Indonesia, merupakan aset yang tidak ternilai harganya, karena kebudayaan daerah itu sebagai bagian dari kebudayaan nasional yang ikut mempengaruhi pertumbuhan dan perkembangan kebudayaan secara nasional (Amin, Syahrul, \& Ermanto, 2013).Negara Indonesia memiliki ratusan jenis sastra daerah yang secara garis besar kekayaan khasanah sastra Nusantara dibagi menjadi tiga, yaitu sastra lisan, sastra tulis, dan sastra modern (Semi, 1993: 3).

Sastra dapat dijadikan sebagai salah satu media untuk menanamkan pendidikan karakter, karena karya sastra mengandung banyak muatan-muatan pesan di dalamnya.Muatan tersebut dapat meliputi muatan kebudayaan, kehidupan sosial, pendidikan, politik, keagamaan, lingkungan hidup, dan aspek-aspek lain dalam kehidupan (Setyawan, Suwandi, \& Slamet, 2017).Salah satu karya sastra yang mengandung banyak muatan pesan adalah legenda.Legenda merupakan salah satu jenis sastra lisan yang berisikan tentang tokoh, peristiwa, atau tempat tertentu yang mencampurkan fakta historis dengan mitos (Amin, Syharul, \& Ermanto, 2013).Sedangkan Emeis dalam Djamaris (1990: 98) menjelaskan bahwa legenda merupakan bagian dari cerita rakyat yang dianggap pernah terjadi, yang mana ceritanya masih kuno dan setengahnya berdasarkan sejarah dan setengahnya lagi angan-angan.Gusal (2015) menyebutkan bahwa legenda juga termasuk bagian dari cerita rakyat yang menampilkan cerita dengan tokoh-tokoh yang hebat yang berada di luar batas-batas kemampuan manusia pada umumnya.Beberapa contoh legenda nusantara adalah legenda gunung takuban perahu di Jawa Barat, legenda danau toba di Sumetra, dan legenda gunung wurung dari Jawa Tengah.

Legenda gunung wurung merupakan salah satu legenda yang berasal dari Kebumen, tepatnya di daerah Karangsambung. Berdasarkan hasil observasi dengan beberapa warga yang berdomisili dekat dengan posisi gunung wurung berada tidak mengetahui akan adanya legenda tersebut, bahkan ada beberapa warga yang belum tahu akan adanya nama gunung wurung di dekat daerahnya. Selanjutnya, hasil dari observasi dengan beberapa guru juga belum mengetahui adanya legenda gunung wurung berasal dari daerah Kebumen.Beberapa faktor yang mempengaruhi ketidaktahuan beberapa warga dan guru adalah legenda gunung wurung tidak 
diceritakan secara turun temurun dan hilang begitu saja, sedangkan beberapa guru yang belum mengetahui adanya legenda gunung wurung di Kebumen dikarenakan kurangnya guru dalam mengintegrasikan materi pembelajaran dengan budaya lokal di Kebumen.Bahkan berdasarkan hasil observasi, guru jarang sekali mengaplikasikan pembelajaran dengan kearifan lokal daerah setempat.

Beberapa penelitian yang telah mengaplikasikan cerita rakyat sebagai media dalam penanaman karakter siswa adalah Setyawan, dkk (2017) menghasilkan temuan bahwa cerita rakyat dari Pacitan memuat nilai-nilai karakter seperti religius, jujur, kerja keras, kreatif, rasa ingin tahu, semangat kebangsaan, menghargai prestasi, cinta damai, peduli lingkungan, peduli sosial, dan tanggung jawab. Cerita rakyat dari Pacitan ini kaya akan nilai pendidikan karakter yang dapat ditanamkan kepada peserta didik seiring dengan pembelajaran terkait secara pendalaman materi, struktur teks, sampai dengan struktur bahasanya. Junaidi (2017) menghasilkan temuan bahwa Cerita Rakyat Andai-andai dari Kedurang mencakup beberapa nilai pendidikan karakter seperti empati sosial, religius, kompilasi, kerja keras, kreativitas, kesabaran, dan menjaga janji. Cerita rakyat ini sangat ideal digunakan sebagai bahan pembelajaran untuk materi sastra karena mengandung banyak nilai pendidikan karakter.Hasil temuan Sayer, dkk (2018) bahwa dongeng dapat dijadikan media dalam meningkatkan karakter kerjasama anak.Selanjutnya Relin, dkk (2018) menghasilkan temuan tentang nilai kearifan lokal dalam cerita Rakyat Bali yang relevan dengan pendidikan karakter kelas I sekolah dasar.

Berdasarkan penjelasan di atas, penelitian ini memfokuskan pada legenda gunung wurung yang dijadikan sebagai media dalam pembentukkan karakter siswa dan sebagai materi/bahan ajar yang berbasis kearifan lokal.

\section{METODE}

Penelitian ini merupakan penelitian deskriptif kualitatif yang menggunakan berbagai sumber dalam mengkaji legenda gunung wurung.Sumber-sumber yang dipakai adalah cerita rakyat tentang legenda gunung wurung dan hasil wawancara dengan warga sekitar daerah Karangsambung.Teknik pengumpulan data yang digunakan adalah observasi, angket, dan wawancara.Selain observasi ke daerah Karangsambung dan interview dengan warga sekitar, juga dilakukan observasi kepada guru di SD Negeri 02 Kuwayuhan untuk mengetahui persepsi guru terhadap legenda gunung wurung.Teknik analisis data menggunakan teknik deskriptif kualitatif.

\section{HASIL DAN PEMBAHASAN}

Legenda gunung wurung merupakan kisah yang menceritakan tentang pembuatan gunung yang belum sampai selesai/belum jadi (bahasa jawa: wurung), sehingga dinamakan dengan nama gunung wurung atau gunung parang sampai saat ini. Legenda gunung wurung secara lengkap dapat dideskripsikan seperti di bawah ini.

\section{Gambaran Umum Legenda Gunung Wurung}

Legenda gunung wurung kononnya berawal dari para sesepuh yang menginginkan adanya gunung di daerang Karangsambung.Di suatu malam yang sunyi senyap, para sesepuh kampung tampak sedang berdoa kepada para dewa di Kahyangan.Dengan penuh khusyuk, mereka memohon agar dibuatkan sebuah gunung di dekat tempat tinggal mereka. Rupanya, doa mereka dikabulkan oleh para dewa. Pembuatan gunung itu akan dimulai besok harinya dan akan dikerjakan dalam waktu semalam. Tetapi dengan syarat, tak seorang pun warga yang boleh melihat pada saat gunung itu dibuat.Para sesepuh kampung menyanggupi persyaratan itu.Keesokan paginya, mereka mengumpulkan para warga untuk menyampaikan berita gembira dan persyaratan tersebut. "Wahai, seluruh wargaku!Kami menghimbau kepada kalian semua agar pada saat hari menjelang senja, masuklah ke dalam rumah kalian masing- 
masing dan tak seorang pun yang boleh keluar rumah hingga matahari terbit besok pagi!" ujar seorang sesepuh kampung. "Maaf, Tuan! Bencana apa yang akan melanda kampung kita? Kenapa kami dilarang keluar rumah?" tanya seorang warga dengan bingung. "Ketahuilah, semua bahwa para dewa akan membuatkan sebuah gunung untuk kita dan tak seorang pun yang boleh melihat ketika mereka sedang bekerja," jelas seorang sesepuh kampung yang lain.Setelah mendengar penjelasan itu, barulah para warga mengerti mengapa mereka dilarang keluar rumah.Ketika hari menjelang senja, suasana kampung mulai sepi.Seluruh warga telah masuk ke dalam rumah dan mengunci pintu rapat-rapat.Tak berapa lama kemudian, para dewa pun turun dari Kahyangan untuk mulai bekerja membangun sebuah gunung di daerah hulu kampung.Mula-mula mereka membangun tiang-tiang yang kokoh.Setelah separuh malam bekerja, para dewa telah selesai membangun tiang-tiang tersebut.Tiang-tiang tersebut kemudian mereka timbuni dengan tanah hingga nantinya membentuk sebuah gunung.Para dewa bekerja sesuai dengan tugas masing-masing tanpa berbicara sepatah kata pun.Mereka terus bekerja hingga larut malam tanpa mengenal lelah.Ketika hari menjelang pagi, pembuatan gunung itu hampir selesai, tinggal menyelesaikan penimbunannya yang tersisa sedikit lagi.Pada saat para dewa masih sibuk bekerja, tiba-tiba dari arah kampung seorang gadis berjalan menuju ke luk ulo (sungai) yang berada di sekitar tempat pembuatan gunung tersebut.Rupanya, gadis itu tidak mengetahui pengumuman tentang larangan keluar rumah pada malam itu. Sebab, pada waktu pengumuman itu disampaikan oleh salah seorang sesepuh kampung, ia tidak hadir dan tak seorang pun warga yang memberitahu tentang hal itu. Gadis itu datang ke sungai karena ingin mencuci beras untuk dimasak.la berjalan tanpa memperhatikan keadaan di sekelilingnya karena suasana masih gelap. Pada saat akan turun ke sungai, gadis itu terperanjat karena tiba-tiba di hadapannya ada sebuah bukit. "Hah, kenapa tiba-tiba ada bukit di tempat ini?Padahal, hari-hari sebelumnya tempat ini masih datar? Ya Tuhan, mimpikah aku ini?" gumam gadis itu seolah tidak percaya terhadap apa yang dilihatnya. Namun, begitu melihat beberapa sosok makhluk yang menyeramkan bergerak cepat sambil mengangkat batu besar tanpa sepatah kata pun, gadis itu langsung berlari meninggalkan sungai karena ketakutan. "Tolooong... Tolooong... Tolong aku!" teriaknya dengan keras.Gadis itu terus berlari tanpa memperdulikan lagi keadaan dirinya sehingga beras yang hendak dicucinya dilemparkan begitu saja.Tak ayal lagi, beras tersebut berceceran di sekitar bukit.Konon, beras tersebut menjelma menjadi bebatuan yang bentuknya mirip dengan beras.Para dewa yang mendengar suara teriakan gadis itu menjadi tersentak.Mereka pun menyadari bahwa ternyata pekerjaan mereka telah disaksikan oleh manusia."Penduduk kampung telah melanggar perjanjian kita.Ayo kita tinggalkan tempat ini!" seru salah satu dewa kepada dewa yang lainnya.Akhirnya, para dewa tersebut menghentikan pekerjaannya.Mereka meninggalkan tempat itu dan bergegas kembali ke Kahyangan.Padahal, pembangunan gunung itu belum selesai.Akhirnya, batallah pembuatan gunung itu.

Berdasarkan kisah tersebut, sebenarnya Gunung wurung/gunung parang merupakan salah satu situs batu berumur lebih dari 100 juta tahun di cagar alam geologi Karangsambung.Lokasi gunung ini berjarak 600 meter di utara kampus LIPI Karangsambung (http://geomagz.geologi.esdm.go.id). 


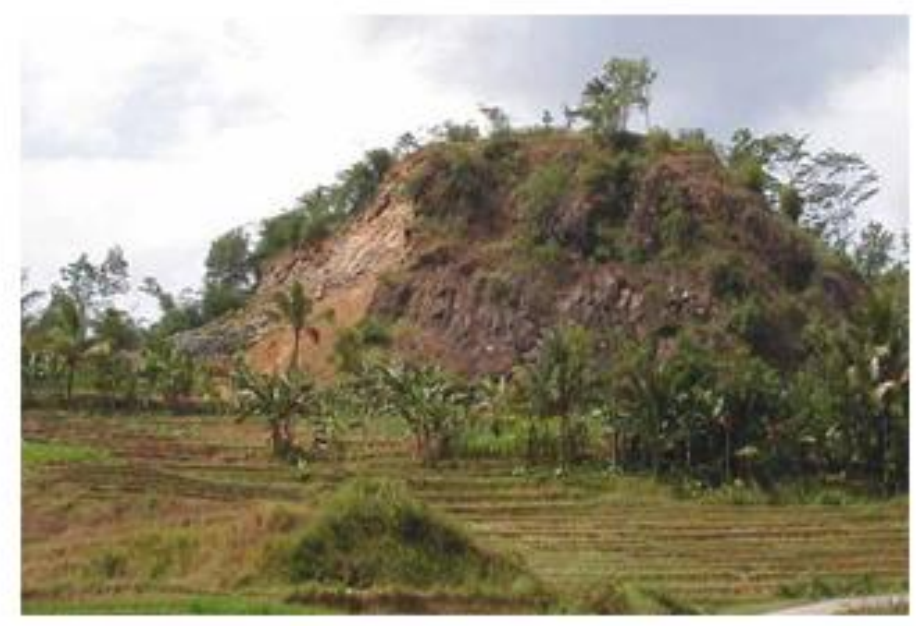

Gambar 1. Struktur Tiang Batu Gunung wurung/gunung parang (columnar joints) (sumber: http://geomagz.geologi.esdm.go.id)

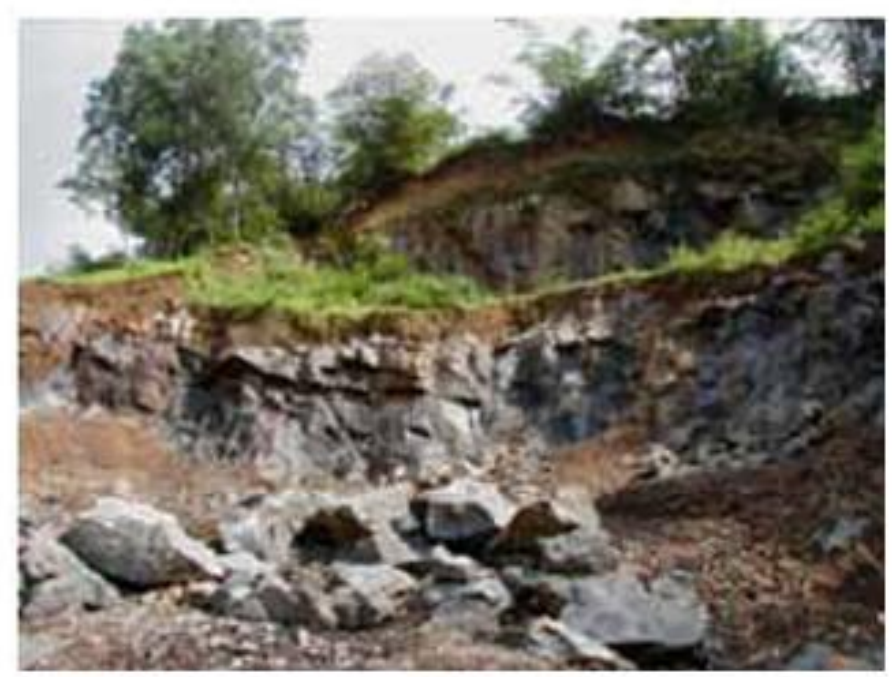

\section{Gambar 2. Penambangan yang ada dibalik Gunung Wurung/Parang}

(sumber: http://geomagz.geologi.esdm.go.id)

Gambar 1 merupakan gambaran dari gunung wurung/parang. Menurut pengertian ilmu geologi, Gunung Parang adalah sebuah intrusi, yaitu magma (bahan gunung api) yang menerobos menuju ke permukaan bumi namun terlanjur membeku sebelum muncul ke permukaan bumi untuk menjadi gunung api. Sejalan dengan waktu, tanah di atas intrusi ini tererosi, sehingga memunculkan Gunung Wurung. Kemiripan cerita rakyat dengan ilmu geologi, Gunung Wurung adalah batuan intrusi (yang batal menjadi gunung api) (http://geomagz.geologi.esdm.go.id). Sedangkan gambar 2 menunjukkan bahwa terdapat kegiatan penambangan yang berlangsung terus menerus pada batuan-batuan khususnya batuan diabas yang merupakan struktur tiang batu (columnar joints) yang dapat menyebabkan rusak/hilangnya cagar alam tersebut.Oleh sebab itu, LIPI terus berupaya memberikan pengertian kepada warga sekitar untuk melakukan penambangan dengan sikap yang arif sehingga tidak sampai mengancam situs cagar alam gunung wurung tersebut. 


\section{Analisis Legenda Gunung Wurung Sebagai Materi/Bahan Ajar Berbasis Kearifan Lokal}

Legenda gunung wurung dapat dijadikan sebagai bahan ajar/materi berbasis kearifan lokal. Prasetyo (2016) menjelaskan bahwa cerita rakyat secara jelas tertulis pada kurikulum 2013 dan kurikulum nasional, menerapkan kebajikan lokal merupakan aspek utama yang harus dimasukkan ke dalam proses pembelajaran. Mengajarkan kebajikan lokal diyakini sebagai salah satu gerakan untuk melestarikan dan mengharagi warisan budaya Indonesia.Selain itu, pembelajaran dengan menggunakan media cerita rakyat/legenda dapat membuat pembelajaran lebih menarik dan menyenangkan serta merangsang rasa ingin tahu siswa.Pembelajaran tematik menjadi ciri utama dalam kurikulum 2013 khususnya di sekolah dasar sehingga sangat tepat jika legenda gunung wurung menjadi tema dalam pembelajaran di sekolah dasar. Gunung wurung dapat dijadikan sebagai tema dengan menggunakan tipe webbed dalam memadukan beberapa materi dari mata pelajaran yang salah satunya ada di kelas III pada tema "Menjaga Kelestarian Lingkungan". Berdasarkan hasil penelitian, $100 \%$ guru memberikan pernyataan setuju jika legenda gunung wurung dijadikan sebagai materi/bahan ajar yang berbasis potensi lokal pada pembelajaran tematik di sekolah dasar.

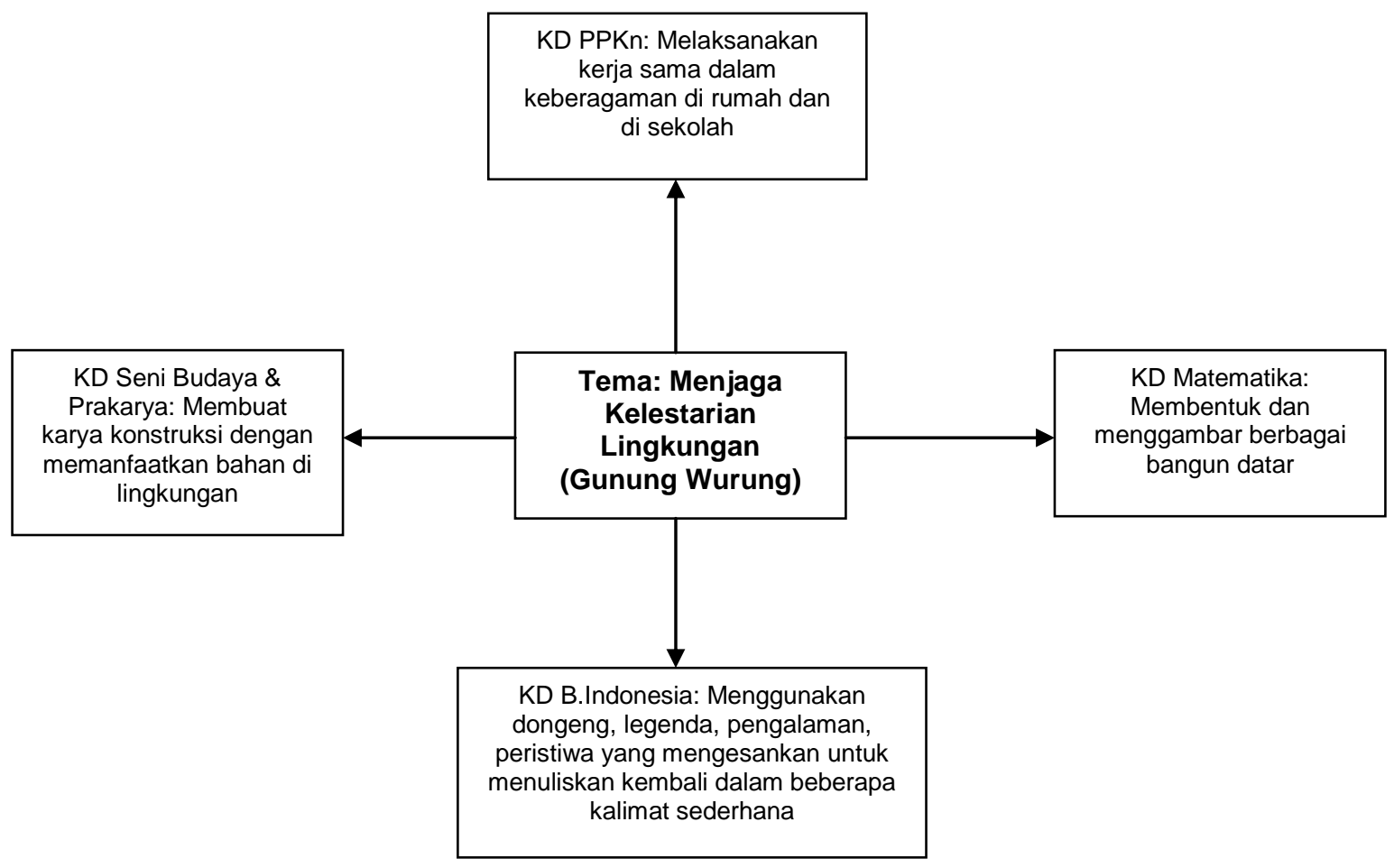

Gambar 3. Contoh Diagram Tipe Webbed dengan Tema Gunung Wurung

Gambar 3 menunjukkan bahwa gunung wurung dijadikan sebagai tema dalam pembelajaran di kelas III khususnya pada tema "Menjaga Kelestarian Lingkungan".Melalui penyisipan legenda gunung wurung pada tema "Menjaga Kelestarian Lingkungan", pembelajaran dapat dilakukan dengan pengenalan potensi lokal yang ada di daerah, khususnya daerah Karangsambung, Kebumen.Pada mata pelajaran PPKn, dapat dijelakan contoh kegiatan kerjasama dalam menjaga 
kelestarian gunung wurung.Mata pelajaran matematika dapat dijelaskan tentang bentuk dan gambar segitiga yang sesuai dengan gambaran gunung wurung. Mata pelajaran bahasa indonesia dapat dijelaskan tentang menuliskan legenda gunung wurung dengan menggunakan kaimat sederhana yang benar. Sedangkan untuk mata pelajaran seni dan prakarya dapat meminta siswa untuk membuat karya yang berhubungan dengan tema pegunungan, khususnya gunung wurung.Seperti membuat maket gunung wurung yang sederhana dengan memanfaatkan bahan-bahan di lingkungan. Selain keempat mata pelajaran di atas, terdapat satu mata pelajaran lagi yaitu Penjasorkes dengan kompetensi dasar Mempraktikkan aktivitas jasmani untuk pengembangan koordinasi, ketepatan, dan daya tahan statis tubuh. Jika dihubungkan dengan tema gunung wurung, mata pelajaran penjasorkes dapat digabungkan saat aktivitas membuat prakarya seperti maket gunung wurung yaitu untuk mengembangkan koordinasi dan ketepatan saat penempelan bahan-bahan dan peletakkan bahan-bahan maket.

Legenda gunung wurung sangat relevan dijadikan sebagai bahan ajar dalam pembelajaran tematik di sekolah dasar.Hal ini sejalan dengan penelitian Junaidi (2017) yang menghasilkan temuan bahwa cerita rakyat sangat relevan digunakan sebagai bahan materi pembelajaran di sekolah dasar.Dilanjutkan oleh Saddhono \& Erwinsyah (2018) menyatakan bahwa cerita rakyat/legenda dapat digunakan sebagai baha ajar di sekolah dalam rangka melestarikan dan memperkenalkan cerita rakyat setempat kepada para siswa. Selain itu, melalui cerita rakyat/legenda mampu memperkenalkan akan adanya budaya lokal di daerahnya ke masyarakat luas yang belum banyak mengetahui. Prasetyo (2016) juga memaparkan bahwa cerita rakyat/legenda penting dikenalkan ke siswa dalam proses pembelajaran karena cerita rakyat/legenda sebagai alat/media untuk membantu siswa memahami bagaimana cara mempertahankan budaya lokal daerahnya.

\section{Analisis Legenda Gunung Wurung Sebagai Penanaman Pendidikan Karakter}

Pendidikan karakter yang paling mudah dilakukan di dunia pendidikan adalah ketika anak-anak masih di bangku Sekolah Dasar (SD). Oleh sebab itu, pemerintah selalu memprioritaskan pendidikan karakter di Sekolah Dasar (Judiani, 2010). Salah satu usaha yang telah dilakukan oleh pemerintah dalam membangun dan mengembangkan pendidikan karakter di sekolah adalah dengan memasukkan muatanmuatan pendidikan karakter di kurikulum pendidikan. Implikasi dari semua itu pendidik dapat menggunakan media berupa cerita rakyat/legenda dalam menumbuhkan karakter anak. Melalui cerita rakyat/legenda yang syarat akan banyaknya pesan-pesan moral, secara tidak langsung akan membentuk pendidikan karakter anak.

Menurut Instruksi Presiden RI nomor 1 tahun 2010 tentang Percepatan Pelaksanaan Prioritas Pembangunan Nasional Tahun 2010 bidang pendidikan yaitu penyempurnaan kurikulum dan metode pembelajaran aktif berdasarkan nilai-nilai budaya bangsa untuk membentuk daya saing dan karakter bangsa. Karakter merupakan watak, tabiat, akhlak, atau kepribadian seseorang yang terbentuk dari hasil internalisasi berbagai kebajikan yang diyakini dan digunakan sebagai landasan untuk cara pandang, berpikir, bersikap, dan bertindak. Karakter tersebut adalah religius, jujur, toleransi, disiplin, kerja keras, kreatif, mandiri, demokrasi, rasa ingin tahu, semangat kebangsaan, cinta tanah air, menghargai prestasi, bersahabat/komunikatif, cinta damai, gemar membaca, peduli lingkungan, peduli sosial, dan tanggung jawab. Samani \& Hariyanto (2012: 138) membagi nilai-nilai karakter ke dalam nilai-nilai pribadi dan nilai sosial.Nilai pribadi terkait dengan kejujuran (keyakinan, keterbukaan, komitmen, tanggung jawab) dan kecerdasan (kreatif, hati-hati, otonom, disiplin, inisiatif, dan kritis).Sedangkan nilai sosial terkait dengan kepedulian (kasih sayang, perhatian, memaafkan orang lain, bersikap ramah, percaya orang lain, dan toleransi) dan 
ketangguhan (ketekunan, antusiasme, kerja keras, kesabaran, sikap tegas, keberanian, dan kebahagiaan).

Legenda gunung wurung sangat tepat digunakan untuk membangun karakter anak yang berbasis potensi lokal sejak dini.Berdasarkan hasil observasi, 100\% guru memberikan pernyataan setuju jika legenda gunung wurung dapat dijadikan media dalam menanamkan pendidikan karakter anak.Beberapa pendidikan karakter yang terkandung dalam legenda gunung wurung berdasarkan hasil persepsi guru seperti penjelasan di bawah ini.

\section{Karakter Religius}

Berdasarkan hasil analisis, $100 \%$ guru memberikan persepsi setuju jika legenda gunung wurung mengandung nilai-nilai religius (nilai agama). Hal ini digambarkan dari penggalan "para sesepuh yang berdoa dan meminta dengan khusyu' untuk dibuatkan gunung di daerahnya". Penggalan ini kaya akan makna tentang keyakinan kepada Tuhan Yang Maha Esa, Tuhan semesta alam. Setyawan, Suwandi, \& Slamet (2017) menjelaskan bahwa nilai religius di dalam karya sastra biasanya bertujuan agar dekat dengan Tuhan dan ajaran agama yang dianutnya, serta memelihara sifat toleran antar sesama umat beragama. Pendidik harus mampu menjelaskan kepada peserta didik tentang Alloh swt, Tuhan yang Maha Esa agar dapat menguatkan karakter religius peserta didik. Hal ini tentunya menjadi tanggung jawab pendidik untuk mampu menjelaskan kepada peserta didik tentang fenomena terjadinya gunung dengan benar. Selain dapat dijelaskan secara agama, fenomena terbentuknya gunung dapat dijelaskan secara sains (IPA).Sehingga guru mampu menjelaskan legenda gunung wurung dari sudut pandang agama dan sains.Pembelajaran dengan menghubungkan materi ke beberapa sudut pandang menjadi pembelajaran yang menarik bagi siswa, karena mampu membantu siswa untuk memiliki wawasan yang lebih luas dalam memahami sebuah fenomena.

\section{Karakter Hormat dan Patuh Kepada Pimpinan}

Karakter pendidikan yang kedua dalam legenda gunung wurung adalah sikap hormat dan patuh kepada pimpinan.Hal ini dapat dilihat pada penggalan "Wahai, seluruh wargaku!Kami menghimbau kepada kalian semua agar pada saat hari menjelang senja, masuklah ke dalam rumah kalian masing-masing dan tak seorang pun yang boleh keluar rumah hingga matahari terbit besok pagi!" ujar seorang sesepuh kampung. "Maaf, Tuan! Bencana apa yang akan melanda kampung kita? Kenapa kami dilarang keluar rumah?" tanya seorang warga dengan bingung. "Ketahuilah, semua bahwa para dewa akan membuatkan sebuah gunung untuk kita dan tak seorang pun yang boleh melihat ketika mereka sedang bekerja," jelas seorang sesepuh kampung yang lain. Setelah mendengar penjelasan itu, barulah para warga mengerti mengapa mereka dilarang keluar rumah.Ketika hari menjelang senja, suasana kampung mulai sepi.Seluruh warga telah masuk ke dalam rumah dan mengunci pintu rapatrapat".Penggalan ini menyiratkan bahwa para warga sekitar sangat hormat dan patuh kepada pimpinan demi kebaikan bersama yaitu melakukan apa yang diperintah oleh pimpinan dengan tidak keluar rumah sampai pagi hari.

\section{Karakter kerja keras}

Karakter kerja keras menjadi nilai pendidikan yang ketiga dalam legenda gunung wurung.Hal ini seperti yang tercantum pada penggalan "para dewa pun turun dari Kahyangan untuk mulai bekerja membangun sebuah gunung di daerah hulu kampung.Mula-mula mereka membangun tiang-tiang yang kokoh.Setelah separuh malam bekerja, para dewa telah selesai membangun tiang-tiang tersebut.Tiang-tiang tersebut kemudian mereka timbuni dengan tanah hingga nantinya membentuk sebuah gunung.Para dewa bekerja sesuai dengan tugas masing-masing tanpa berbicara sepatah kata pun.Mereka terus bekerja hingga larut malam tanpa mengenal lelah".Karakter kerja keras terlihat pada bagaimana para dewa dengan semangat dan 
kerja keras untuk dapat menyelesaikan pekerjaan membuat gunung dalam waktu 1 malam.

\section{Karakter kerja sama}

Karakter kerja sama menjadi nilai pendidikan karakter yang keempat pada legenda gunung wurung seperti yang tercantum pada penggalan "Mula-mula mereka membangun tiang-tiang yang kokoh. Setelah separuh malam bekerja, para dewa telah selesai membangun tiang-tiang tersebut.Tiang-tiang tersebut kemudian mereka timbuni dengan tanah hingga nantinya membentuk sebuah gunung. Para dewa bekerja sesuai dengan tugas masing-masing tanpa berbicara sepatah kata pun". Karakter kerja sama terlihat bagaimana para dewa secara bersama-sama bergotong royong untuk membangun sebuah gunung dan bekerja sesuai dengan tugasnya masing-masing agar pekerjaan dapat segera selesai.

\section{Karakter Peduli Sosial}

Karakter peduli sosial atau peduli ke sesama menjadi karakter kelima yang terkandung dalam legenda gunung wurung.Nilai peduli sosial dapat dilihat pada penggalan "Pada saat para dewa masih sibuk bekerja, tiba-tiba dari arah kampung seorang gadis berjalan menuju ke luk ulo (sungai) yang berada di sekitar tempat pembuatan gunung tersebut.Rupanya, gadis itu tidak mengetahui pengumuman tentang larangan keluar rumah pada malam itu.Sebab, pada waktu pengumuman itu disampaikan oleh salah seorang sesepuh kampung, ia tidak hadir".Karakter peduli sosial di kisah ini digambarkan dengan kurangnya kepedulian seorang wanita tentang agenda-agenda/kegiatan yang ada di lingkungannya sehingga mengakibatkan dampak yang tidak baik. Sikap peduli sosial perlu dipupuk sejak kecil karena melalui kepedulian yang tinggi kepada sesama, anak akan belajar menghargai dan dihargai oleh sesama sehingga akan terhindar dari sikap egois dan individualisme yang pada akhirnya dapat merugikan diri sendiri bahkan masyarakat, seperti yang dikisahkan dalam legenda gunung wurung hanya karena kesalahan yang dilakukan oleh seorang perempuan berdampak buruk bagi seluruh warga sekitar.

\section{Karakter kesabaran}

Karakter kesabaran menjadi menjadi karakter keenam pada kisah legenda gunung wurung, yaitu seperti yang tercantum pada penggalan " WWahai, seluruh wargaku! Kami menghimbau kepada kalian semua agar pada saat hari menjelang senja, masuklah ke dalam rumah kalian masing-masing dan tak seorang pun yang boleh keluar rumah hingga matahari terbit besok pagi!'. Karakter kesabaran pada kisah ini digambarkan dengan seluruh warga yang dengan ikhlas tidak keluar rumah selama satu malam sampai menjelang pagi.

\section{Karakter Komitmen}

Karakter komitmen menjadi karakter ketujuh pada kisah legenda gunung wurung yaitu seperti yang terlihat pada penggalan "Pembuatan gunung itu akan dimulai besok harinya dan akan dikerjakan dalam waktu semalam. Tetapi dengan syarat, tak seorang pun warga yang boleh melihat pada saat gunung itu dibuat.Para sesepuh kampung menyanggupi persyaratan itu".Penggalan ini menggambarkan tentang komitmen terhadap sebuah janji yang tentunya harus ditepati oleh seluruh warga.

\section{SIMPULAN}

Hasil analisis menunjukkan bahwa: 1) Legenda gunung wurung ternyata kurang dikenal bagi warga sekitar daerah Karangsambung; 2) Legenda gunung wurung dapat dijadikan sebagai alternatif bahan materi dalam pembelajaran tematik di SD yang berbasis kearifan lokal; 2) Nilai-nilai pendidikan karakter pada legenda gunung wurung meliputi karakter religius, hormat dan patuh, kerja sama, kerja keras, peduli sosial, kesabaran, dan komitmen/menepati janji. Rekomendasi dalam penelitian ini adalah pembelajaran perlu menekankan pada potensi lokal yang ada di daerah masingmasing sehingga anak didik memahami warisan dari kebudayaan daerahnya.Di daerah 
Kebumen sangat banyak warisan budaya yang perlu dilindungi dan disebarluaskan. Selain legenda gunung wurung, asal usul nama daerah Kebumen, cerita rakyat nyai ronggeng, dan legenda desa logandu dapat dijadikan beberapa alternatif dalam pembelajaran tematik bagi siswa sekolah dasar, khususnya pembelajaran bahasa.

\section{DAFTAR PUSTAKA}

Amin, I., Syahrul, \& Ermanto. (2013). Cerita Rakyat Penamaan Desa di Kerinci: Kategori dan Fungsi Sosial Teks. Jurnal Bahasa, Sastra, dan Pembelajaran, 1 (1): 31-41.

Djamaris, E. (1990). Menggali Khazanah Sastra Melayu Klasik (Sastra Indonesia Lama). Jakarta: Balai Pustaka.

Gusal, L.O. 2015.Nilai-Nilai Pendidikan dalam Cerita Rakyat Sulawesi Tenggara Karya La Ode Sidu.Jurnal Humanika, 3 (15).

Gusnetti, Syofiani, \& Isnanda R. (2015).Struktur dan Nilai-Nilai Pendidikan dalam Certa Rakyat Kabupaten Tanah Datar Provinsi Sumatera Barat. Jurnal Gramatika: Jurnal Penelitian Bahasa dan Sastra Indonesia VI, 183-192.

Instruksi Presiden RI nomor 1 tahun 2010 tentang Percepatan Pelaksanaan Prioritas Pembangunan Nasional.

Judiani, S. (2010).Implementasi Pendidikan Karakter di Sekolah Dasar Melalui Penguatan Pelaksanaan Kurikulum.Jurnal Pendidikan dan Kebudayaan, 16 (III), 280-289.

Junaidi. (2017). The Value of Characteristic in Andai-Andai Folklore and its Use As Learning Material for Literature Subject in Elementary School. International EJournal of Advances in Education, III (9), 501-509.

Munasri.(2011). Karangsambung Laboratorium Alam Geologi. Geomagz: Majalah Populer Geologi Populer. Diunduh dalam http://geomagz.geologi.esdm.go.id/karangsambung-laboratorium-alam-geologi/ pada tanggal 12 Oktober 2018.

Oktarina, R. \& Ribuwati.(2018). Penerapan Pendidikan Berbasis Kearifan Lokal di SD Negeri 8 Rambutan Kabupaten Banyuasin Menuju Global Citizen. Prosiding Seminar Nasional 21 Universitas PGR Palembang 2018, 589-594.

Peraturan Pemerintah RI Nomor 19 Tahun 2005 tentang Standar Nasional Pendidikan.

Prasetyo, A. (2016). Folklore in EFL: The Local Wisdom Implementation of Indonesian Curriculum. Journal of ELT Reseach, 1 (2), 194-199.

Relin, Rasna, \& Binawati.(2018). Local Wisdom Values in Balinese Folktales that are Relevant to Character Education for the First Grade at Primary Schools. Journal of Languange Teaching and Research, 9 (1), 155-163.

Saddhono, K. \& Erwinsyah, H. (2018). Folklore As Local Wisdom for Teaching Materialsin Bipa Program (Indonesian for Foreign Speakers). Internasional Conference on Social and Political Issues (the 1st ICSPI 2016) "Knowledge and Social Transformation", 444-454.

Samani \& Hariyanto.(2012). Konsep dan Model Pendidikan Karakter. Bandung: PT Remaja Rosdakarya Offset.

Sayer, I.M., Kristiawan, M., \& Agustina, M. 2018.Fairy Tale as Medium for Children's Character Cooperation Building. Al-Ta'lim Journal, 25 (2), 108-116.

Setyawan, Suwandi, \& Slamet.(2017). Muatan Pendidikan Karakter dalam Cerita Rakyat di Pacitan. Komposisi: Jurnal Pendidikan Bahsa, sastra, dan Seni., XVIII (1), 90-106.

Semi, A. (1993).Rancangan Pengajaran Bahasa dan Sastra Indonesia. Bandung: Angkasa. 